\title{
Comparison of maternal-neonatal results of vaginal birth after cesarean and elective repeat cesarean delivery
}

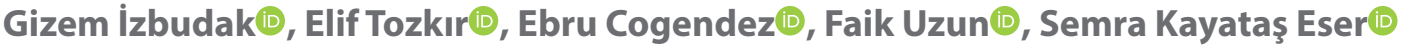 \\ Department of Obstetrics and Gynecology, Health Sciences University, Zeynep Kamil Women's \\ and Children's Diseases Training and Research Hospital, Istanbul, Turkey
}

\begin{abstract}
Objective: To evaluate maternal-neonatal results in women who underwent vaginal birth after cesarean (VBAC) and elective repeat cesarean delivery (ERCD).

Material and methods: In a two-year retrospective cohort analysis, 423 patients with a history of prior cesarean section, singleton pregnancy with cephalic presentation and gestational age of 37-41 weeks were investigated. The maternal and perinatal outcomes of 195 patients desiring VBAC and undergoing a trial of labor after cesarean (TOLAC) attempt and 228 patients undergoing an ERCD were compared.

Results: While the TOLAC attempt was successful in 141 patients (72.3\%), it was unsuccessful in 54 patients. No statistically significant difference was determined between VBAC and ERCD patients regarding uterine rupture, dehiscence, post-partum hemorrhage, the need for a blood transfusion and wound site infection $(p>0.05)$. When the post-partum neonatal outcomes were compared, there was no statistically significant difference between VBAC and ERCD groups regarding the prevalence of admission to the neonatal intensive care unit (NICU), respiratory distress, sepsis and birth injury ( $p>0.05)$.

Conclusion: The maternal and perinatal outcomes of our study may be encouraging in favor of VBAC particularly in countries with higher cesarean rates. We think that the option of VBAC should be offered more frequently for selected appropriate patients in created safe environments.
\end{abstract}

Key words: vaginal birth after cesarean; trial of labor after cesarean; maternal morbidity; maternal mortality; neonatal morbidity; neonatal mortality

Ginekologia Polska 2021; 92, 4: 306-311

\section{INTRODUCTION}

Although the cesarean delivery rates show wide variability by different countries and as a matter of fact in the same country according to the different institutions, it is associated with a substantial increase in recent years. Many reasons such as the widespread use of electronic fetal heart rate monitoring, reduction in operative vaginal deliveries and breech vaginal deliveries contributed to this increase [1]. Also, elective repeat cesarean sections performed due to a previous history of cesarean section increase the cesarean delivery rates dramatically. Thus, the cesarean delivery with a prior cesarean delivery was reported to be the most common indication for cesarean in $30-50 \%$ of all deliveries in the United States [2].

Flamm and Geiger developed a scoring system to predict the likelihood of vaginal birth for women who were desiring VBAC using the present factors at the time of hospital admission in 1997 [3]. Subsequently, Grobman et al. developed a model based on the present factors at the first visit for the prediction of a successful TOLAC attempt [4]. Although VBAC was considered a solution against increased cesarean rates for a long time, a reduction occurred in the trend of VBAC trials in the past two decades. While the reason for this is not known exactly, it is thought that many factors such as the patient's preference, institutional protocols, national guidelines, and the fear of litigation cause this condition [5].

American College of Obstetricians and Gynecologists (ACOG) published VBAC guidelines in 2019 and reported that the nomogram of Grobman et al. [6] reflected the real possibility for many populations and provided more specific information about the chance of VBAC, but none of

\section{Corresponding author:}

Ebru Cogendez

Department of Obstetrics and Gynecology, Health Sciences University, Zeynep Kamil Women's and Children's Diseases Training and Research Hospital,

Dr. Burhanettin Üstünel Street No:10, Uskudar, 34668 Istanbul, Turkey

e-mail:ebrucogendez@gmail.com 
the estimation models resulted in improvement in patient outcomes.

\section{Objectives}

The meticulous selection of the patient population in which TOLAC attempt can be successful is of vital importance. The uterine rupture, which is a worrying complication of the TOLAC attempt, is the most effective factor for moving away from the TOLAC option. The aim of this study was to compare neonatal and maternal outcomes in women going forTOLAC/VBAC versus those with an elective repeat cesarean section. The fact that VBAC gives results comparable to ERCD for mother and newborn will lead to further support of VBAC in the future, which will contribute to the reduction of placental invasion anomalies rates.

\section{MATERIAL AND METHODS}

Our study was performed in patients with a gestational age of 37-41 weeks and a history of a prior cesarean section who presented to the emergency room and admitted to the delivery room of the University of Health Sciences, Zeynep Kamil Women's and Children's Disease Training and Research Hospital. Last menstrual period and first-trimester ultrasound records were evaluated together for the determination of being term pregnancy. The birth registries of patients between November 2015 and May 2017 were retrospectively evaluated. TOLAC and ERCD were performed in 195 and 228 patients, respectively. Our study was approved by the local Research Ethics Committee. All patients were informed, and written consent was obtained from all of them before any study-related procedures were performed.

During routine pregnancy follow-ups, all patients were first admitted to the maternity follow-up outpatient clinics. VBAC and ERCD options were offered to patients who had a previous cesarean birth history and have no contraindications for normal delivery. Patients who wanted to get information about VBAC were directed to our spesific VBAC clinic, which played an important role in patients' VBAC/ /TOLAC preferences. When patients had a thorough counseling including advantages and risks of both forms of delivery in an adequate time, their preferences shifted from ERCD to VBAC/TOLAC. The data of the patients who underwent TOLAC procedure were obtained from VBAC clinical records

Suitability for vaginal delivery in our VBAC patients was determined according to ACOG guidelines [7]. Accordingly, the TOLAC attempt was performed in our patients with a history of delivery using a lower uterine segment transverse incision, with adequate pelvic dimensions, without a history of another uterine scar or rupture under normal delivery room conditions of our hospital. Concerning patients undergoing a TOLAC attempt, the women with a period of more than at least 24 months after previous cesarean delivery were included in the study. The patients with a previous classical or inverted T-shaped incision on the uterus, a history of extensive transfundal uterine surgery, a history of previous uterine rupture, medical or obstetrical complications which were barriers to vaginal delivery, nonvertex presentation, fetal anomaly, multiple pregnancies, placenta previa, vasa previa and decollement placenta were excluded from the study. The patients without complaints of pain at the presentation, no cervical opening at the vaginal examination, no uterine contraction at non-stress test assessments were included in the ERCD group.

Spontaneous onset of active-phase labor was accepted as the case with a cervical dilatation of more than $4 \mathrm{~cm}$ at the time of admission in the hospital. Again, it has been understood from the file registries that induction was achieved with an obstetric indication using prostaglandin E2 vaginal ovule or a low-dose oxytocin protocol in some of the patients in the TOLAC group.. Among maternal morbidities, while major complications were defined as uterine rupture and dehiscence, post-partum hemorrhage, peripartum hysterectomy, bladder or bowel injury; minor complications were defined as the need for a blood transfusion, wound site infection and puerperal fever. While the uterine rupture was defined as a full-thickness separation of both the myometrium and visceral peritoneum, dehiscence was defined as the presence of an intact serosa despite a complete separation of the myometrium. Post-partum hemorrhages were determined as hemorrhages requiring additional medical or surgical intervention other than standard procedures during the follow-up after delivery. Puerperal fever was considered as body temperature exceeding $37.5^{\circ} \mathrm{C}$ and concomitant wound site infection, endometritis, pulmonary infection, and urinary infections. Post-partum mobilization period, post-partum hospital discharge period, prepartum and post-partum hematocrit values were compared between groups. While the incidence of anesthesia complications was evaluated in the ERCD group and the incidences of operative delivery and perineal laceration were evaluated in the VBAC group.

The admission to the NICU, birth injury, sepsis, and respiratory distress were compared between groups as neonatal morbidity. Additionally, the fifth minute Apgar scores of the neonate were also investigated in both groups.

\section{Statistical analysis}

The data were analyzed with SPSS for Windows 23.0 version. Average, standard deviation in descriptive statistics of continuous variables; categorical variables were expressed in numbers and percentages. The significance of the difference between the groups for categorical variables was evaluated with the Chi-Square test. Student's T test was used in the analysis of data with normal distribution in 
binary group comparisons, and Mann Whitney-U test was used in data without normal distribution. The significance of the difference between repeating measurements was calculated with Paired Samples T test. The independent effect of each factor on the data that may be affected by more than one factor was evaluated by logistic regression analysis. Odds Ratio (OR) was calculated for risk analysis of risk factors. $P<0.05$ value was considered statistically significant.

\section{RESULTS}

The demographic characteristics of the patients were shown in Table 1. The mean age was found to be similar in both groups. The gestational week was greater in the VBAC group $(p<0.001)$. Body mass index was found to be statistically significantly greater in favor of $\operatorname{ERCD}(p=0.035)$. Comparisons of the groups according to the number of their previous vaginal deliveries and abortions were shown in Table 2.

While the spontaneous onset of active-phase labor was present in 75 patients (38.5\%) of the VBAC group; it was

\begin{tabular}{|c|c|c|c|}
\hline & TOLAC (n: 195) & ERCD (n: 228) & $P$ value \\
\hline Age (year) & $29.7 \pm 5.2$ & $29.3 \pm 5.2$ & $0.422^{*}$ \\
\hline Gestational week & $39.6 \pm 1.14$ & $39.1 \pm 0.6$ & $<0.001 * *$ \\
\hline $\mathrm{BMI}$ & $29 \pm 3.9$ & $29.9 \pm 4.5$ & $0.035^{*}$ \\
\hline
\end{tabular}

BMI - Body mass index

*Student's t test; **Mann Whitney U test understood that 120 patients (61.5\%) were admitted to the delivery room without the onset of active-phase labor. It was determined that induction of labor was performed with low-dose oxytocin, prostaglandin E2-dinoprostone vaginal ovule in $63(32.3 \%)$ and 7 patients (3.6\%), respectively and no induction agent was administered in 132 patients (64.1\%) in the VBAC group. While uterine rupture was detected in 1 patient who underwent low-dose labor induction with oxytocin, uterine rupture was not observed in any of the other patients. Operative delivery was performed using ${ }^{\circ}$ Kiwi OmniCup Vacuum Delivery System, vacuum extraction and forceps in 11 (5.6\%), 10 (5.1\%) and 4 patients $(2.1 \%)$, respectively in the VBAC group. Third degree perineal laceration occurred in 5 (2.6\%) patients; only two of them were observed after operative delivery. There were no deaths in either group.

A comparison of post-partum maternal outcomes between VBAC and ERCD groups was shown in Table 3. While post-partum hematocrit values were found to be significantly lower in both groups compared to prepartum hematocrit values $(p<0.001)$; the reduction rate was determined to be similar in both groups $(p=0.433)$.

A comparison of maternal morbidity outcomes between groups was shown in Table 4. There was no significant difference between groups regarding uterine rupture, dehiscence, post-partum hemorrhage, the need for a blood transfusion and wound site infection ( $p>0.05)$. Peripartum hysterectomy, bowel and bladder injury were observed in none of the patients in both groups. Anesthesia complication was observed in three patients of the ERCD group. While difficult intubation and correspondingly transient desatura-

\begin{tabular}{|c|c|c|c|}
\hline & TOLAC (n: 195) & ERCD (n: 228) & $\mathbf{p}$ \\
\hline Number of previous NVD (n) & & & $0.272^{*}$ \\
\hline 0 & 152 (43.9\%) & 194 (56.1\%) & \\
\hline 1 & $28(57.1 \%)$ & $21(42.9 \%)$ & \\
\hline 2 & $9(64.3 \%)$ & $5(35.7 \%)$ & \\
\hline 3 & $4(40 \%)$ & $4(40 \%)$ & \\
\hline 4 & $1(100 \%)$ & 0 & \\
\hline 5 & 0 & $1(100 \%)$ & \\
\hline 6 & $1(50 \%)$ & $1(50 \%)$ & \\
\hline Abortion number (n) & & & $0.027^{*}$ \\
\hline 0 & $161(49.5 \%)$ & $164(50.5 \%)$ & \\
\hline 1 & 25 (35.7\%) & 45 (64.3\%) & \\
\hline 2 & $5(27.8 \%)$ & $13(72.2 \%)$ & \\
\hline 3 & $3(37.5 \%)$ & $5(62.5 \%)$ & \\
\hline 4 & $1(50 \%)$ & $1(50 \%)$ & \\
\hline
\end{tabular}

*Ki-kare test; $p<0.05$ is statistically significant; NVD — Normal vaginal delivery 


\begin{tabular}{|c|c|c|c|}
\hline & TOLAC (n: 195) & ERCD (n: 228) & $P$ value \\
\hline $\begin{array}{l}\text { Postpartum } \\
\text { fever }\left({ }^{\circ} \mathrm{C}\right)\end{array}$ & $36.6 \pm 0.3$ & $36.5 \pm 0.3$ & 0.030 \\
\hline $\begin{array}{l}\text { Mobilization } \\
\text { time (hours) }\end{array}$ & $3.7 \pm 1.8$ & $5.7 \pm 2.3$ & $<0.001$ \\
\hline $\begin{array}{l}\text { Postpartum } \\
\text { discharge time } \\
\text { (hours) }\end{array}$ & $35.5 \pm 16.7$ & $45 \pm 15$ & $<0.001$ \\
\hline
\end{tabular}

\begin{tabular}{|c|c|c|c|}
\hline & TOLAC (n: 195) & ERCD (n: 228) & $P$ value \\
\hline Uterine rupture & $1(0.5 \%)$ & 0 & 0.233 \\
\hline $\begin{array}{l}\text { Uterine } \\
\text { dehiscence }\end{array}$ & $3(1.5 \%)$ & $2(0.9 \%)$ & \\
\hline $\begin{array}{l}\text { Need for } \\
\text { transfusion }\end{array}$ & $6(3.1 \%)$ & $1(0.4 \%)$ & 0.052 \\
\hline $\begin{array}{l}\text { Postpartum } \\
\text { hemorrhage }\end{array}$ & $9(4.6 \%)$ & $5(2.2 \%)$ & 0.132 \\
\hline Wound infection & $3(1.5 \%)$ & $5(2.2 \%)$ & 0.731 \\
\hline
\end{tabular}

*Ki-kare test

tion were observed in one of them, transient desaturation immediately after intubation due to pulmonary secretions was seen in one patient. Laryngeal edema and dyspnea developed after extubating in the last case determined to have a polyp at the base of the tongue during inspection before intubation. This last patient was re-intubated urgently during the post-operative period and admitted to the adult intensive care unit.

No significant difference was determined between the VBAC and ERCD groups regarding admission to the NICU, respiratory distress, sepsis and birth injury $(p>0.05)$. Respiratory distress was observed in the neonate of one patient developing uterine rupture. In the VBAC group, while clavicle fracture secondary to shoulder dystocia occurred in one neonate, a cephalic hematoma developed due to vacuum extraction in one newborn. Neonatal death occurred in none of these groups.

In the VBAC group, while the TOLAC attempt was successful in 141 patients, it was unsuccessful in 54 patients. The gestational week was determined to be significantly greater in women with unsuccessful TOLAC attempts ( $p>0.001)$. Indications for repeated cesarean section in patients with unsuccessful TOLAC attempts were as following: Cephalopelvic disproportion (CPD) in 5 patients (9.2\%), fetal distress in 10 patients (18.5\%), unreliable nonstress test (NST) in 9 patients (16.6\%), prolonged labor in 12 patients
(22.2\%), cord prolapsus in 1 patient (1.8\%), patient's request in 13 patients (refusing TOLAC attempt) (24\%), suspicion for the uterine rupture in 3 patients $(5.5 \%)$, prolonged premature rupture of membranes in 1 patient (1.8\%). The uterine rupture in 1 patient and dehiscence in 1 patient were determined in patients undergoing cesarean section with an indication of suspicion of rupture of membranes. The factors affecting the success of the TOLAC attempt were shown in Table 5.

\section{DISCUSSION}

With dramatically increasing rates in the actual course of the disease, cesarean deliveries are encountered as one of the most current problems in obstetrics. In 1980, Bottoms et al. [8] emphasized that elective cesarean sections performed due to a previous history of cesarean delivery provided a significant contribution to increasing cesarean rate. Therefore, deciding on a trial of labor in a subsequent pregnancy after cesarean delivery will affect future pregnancies. It has been shown that maternal morbidity increased progressively with an increasing number of cesarean deliveries and there was a dose-response relationship between placenta accreta and the number of previous cesarean deliveries particularly in the presence of placenta previa [9]. For this reason, decisions related to the TOLAC attempt will affect the outcomes of future pregnancies.

The VBAC clinic was opened in our hospital in 2015 to reduce the increased cesarean rates in our country. In our study, TOLAC preference was found to be very high (90.2\%) in patients who applied to the VBAC clinic. We believe the most effective factor in this preference is giving a thorough counseling about the advantages and risks of both forms of delivery to patients with a previous cesarean delivery history in adequate time. In our study, the TOLAC success rate was determined to be $72.3 \%$. This rate was comparable to the rates of $73 \%$ in the meta-analysis of Rossi and D'Addario and $74 \%$ in NIH statement $[10,11]$. Hence, the TOLAC success rate was reported to be between $68 \%$ and $83 \%$ also in the studies of other authors [12-14].

Our uterine rupture rate was $0.5 \%$ and it was comparable to the rate of $0.3 \%$ obtained from the systematic review of Guise et al. and reported by McMahon et al. [15]. In the study performed by Shipp et al. [16], the rate of uterine rupture was reported to be $2.3 \%$ when the inter delivery interval was less than 18 months and $1 \%$ when it was more than 18 months. Soni et al. [17] reported that the low rate of uterine rupture $(0.4 \%)$ in their study was due to intrapartum intensive monitoring with appropriate patient selection and early recognition of dehiscence or rupture.

Again, in our study, peripartum hysterectomy, bowel, and bladder injury among major complications were observed in none of the patients. In a recent study performed 


\begin{tabular}{|c|c|c|c|}
\hline \multirow{2}{*}{ Pregnancy features } & Successful TOLAC (n: 141) & Failed TOLAC (n: 54) & OR \\
\hline & n (\%) & $n(\%)$ & $95 \% \mathrm{Cl}$ \\
\hline \multicolumn{4}{|l|}{ Maternal age } \\
\hline$\leq 19$ & $2(1.4 \%)$ & $2(3.7 \%)$ & $0.53(0.06-4.69)$ \\
\hline $20-24$ & $21(14.9 \%)$ & $4(7.4 \%)$ & $2.18(0.63-7.56)$ \\
\hline $25-29$ & $51(36.2 \%)$ & $24(44.4 \%)$ & $1^{*}$ \\
\hline $30-34$ & $42(29.8 \%)$ & $13(24.1 \%)$ & $1.55(0.66-3.61)$ \\
\hline$\geq 35$ & $25(17.7 \%)$ & $11(20.4 \%)$ & $0.72(0.26-1.95)$ \\
\hline \multicolumn{4}{|c|}{ Number of previous NVD } \\
\hline 0 & $105(74.5 \%)$ & $47(87 \%)$ & $1^{*}$ \\
\hline 1 & $24(17 \%)$ & $45(\% 64.3)$ & $3.33(0.97-11.36)$ \\
\hline$\geq 2$ & $12(8.5 \%)$ & $3(5.6 \%)$ & $2.07(0.44-9.62)$ \\
\hline \multicolumn{4}{|l|}{ Birth weight } \\
\hline$<2500 \mathrm{~g}$ & $3(2.1 \%)$ & - & - \\
\hline $2500-2999 \mathrm{~g}$ & $32(22.7 \%)$ & $5(9.3 \%)$ & $1.88(0.62-5.65)$ \\
\hline $3000-3499 \mathrm{~g}$ & $65(46.1 \%)$ & $21(38.9 \%)$ & $1^{*}$ \\
\hline $3500-3599 \mathrm{~g}$ & $35(24.8 \%)$ & $23(42.6 \%)$ & $0.48(0.22-1.04)$ \\
\hline$\geq 4000 \mathrm{~g}$ & $6(4.3 \%)$ & $5(9.3 \%)$ & $0.43(0.11-1.64)$ \\
\hline \multicolumn{4}{|c|}{ Spontaneous onset labor } \\
\hline present & 74 (61.7\%) & 46 (38.3\%) & $1^{*}$ \\
\hline absent & 67 (89.3\%) & $8(10.7 \%)$ & $5.21(2.29-11.82)$ \\
\hline
\end{tabular}

*Reference category; OR — Odds Ratio; $\mathrm{Cl}$ — Confidence interval; NVD — Normal vaginal delivery

by Bellows et al. [18], TOLAC patients before and after ACOG 2010 VBAC guidelines were compared; while the rate of hysterectomy in TOLAC attempts before guidelines was $1.1 \%$, this rate was reported to be $0.1 \%$ after guidelines. This difference was found to be significant $(p=0.03)$.

In our study, mean postpartum mobilization and discharge time were found earlier and shorter respectively in successful TOLAC cases compared to ERCD cases $(p<0.001)$. Our data support the data of the National Institutes of Health stating that TOLAC is associated with a shorter hospitalization period [10].

In the literature, no randomized-controlled studies comparing neonatal outcomes with a high evidence level of TOLAC and ERCD are available. Data in some available studies are also controversial, however, when we evaluate generally, it is mentioned about the risk for sepsis and admission to NICU is increased in the TOLAC group and the risk for laceration-related birth injuries and TTN is increased in the ERCD group $[19,20]$. In our study, no neonatal death was observed in our patients. The neonate of a patient developing uterine rupture was admitted to the NICU due to respiratory distress and discharged with full recovery after 14 days.

The uterine rupture is the complication causing the major concern for either patient or clinician in the TOLAC attempt. It has been reported in many studies that the risk of the uterine rupture increased markedly in the unsuccessful TOLAC attempt. Thus, we also observed that this risk increased 8.3-fold in women with unsuccessful TOLAC attempts. While this rate was reported to be 3.7-fold by Mc Mahon et al. [15], Landon et al. [21] reported this rate as 22.1-fold for the uterine rupture and as 14.8-fold dehiscence.

In our study, we determined that the factors affecting the success of TOLAC attempt as age, birth weight, the number of previous vaginal delivery and the presence of spontaneous onset of active-phase labor. When we take the 25-29 age range as a reference for maternal age, we observe that the likelihood of success of TOLAC attempt increases 2.18-fold in the age range of 20-24 years and 1.55-fold in the age range of 30-34 years. The success of the TOLAC attempt decreases under the age of 19-year-old and over the age of 35-year-old. When we take the patients without a previous vaginal delivery as a reference, while the likelihood of successful TOLAC attempt increases 3.33-fold in women with a previous vaginal delivery, this rate increases 2.07-fold in women with two or more previous vaginal deliveries. Again, similarly, we determined that the likelihood of successful TOLAC attempt increased 5.21-fold in women admitted to the delivery room due to the spontaneous onset of active-phase labor. These findings were also consistent 
with the data of the study performed by Senturk et al. [22] and titled "factors associated with successful vaginal birth after the cesarean section". When we take the 3000-3499 g as a reference for birth weight, we observe that the likelihood of success of the TOLAC attempt increases 1.88-fold in the birth weight range of 2500-2999 $\mathrm{g}$ and the likelihood of success of TOLAC attempt progressively decreases over the birth weight of 3,500 and 4,000 g.

One of the major limitations of our study is having insufficient information from our patients about cesarean indication at previous cesarean delivery. Unknown indications about previous cesarean delivery which could be a factor increasing our TOLAC failure. The reason for this in the studies performed was reported to be an indication for the previous cesarean section that could not be repeated in subsequent pregnancies was a factor increasing TOLAC success [23,24]. The other limitation of our study is the small numbers per groups which might lead to scarce adverse effects.

\section{CONCLUSIONS}

Developing countries like us have a high cesarean section rate. In our changing world our practice also needs to change for the better. Although it is impossible to predict TOLAC success yet, the maternal and perinatal outcomes of our study show that VBAC is a reliable mode of delivery in case of the creation of safe environments and meticulous selection of the candidates. To be able to prevent increasing cesarean rates, we think that the option of VBAC should be offered more frequently for selected appropriate patients.

\section{Conflict of interest}

All authors declare that they have no conflict of interest.

\section{REFERENCES}

1. Hamilton BE, Martin JA, Osterman MJ, et al. Births: provisional data for 2016. Vital Statistics Rapid Release No 2. Hyattsville (MD): National Center for Health Statistics; 2017.

2. Cheng YW, Eden KB, Marshall N, et al. Delivery after prior cesarean: maternal morbidity and mortality. Clin Perinatol. 2011; 38(2): 297-309, doi: 10.1016/j.clp.2011.03.012, indexed in Pubmed: 21645797.

3. Flamm BL, Geiger AM. Vaginal birth after cesarean delivery: an admission scoring system. Obstet Gynecol. 1997; 90(6): 907-910, doi: 10.1016/s0029-7844(97)00531-0, indexed in Pubmed: 9397100.

4. Grobman WA, Lai Y, Landon MB, et al. National Institute of Child Health and Human Development (NICHD) Maternal-Fetal Medicine Units Network (MFMU). Development of a nomogram for prediction of vaginal birth after cesarean delivery. Obstet Gynecol. 2007; 109(4): 806-812, doi: 10.1097/01.AOG.0000259312.36053.02, indexed in Pubmed: 17400840.

5. Lundgren I, Smith V, Nilsson C, et al. Clinician-centred interventions to increase vaginal birth after caesarean section (VBAC): a systematic review. BMC Pregnancy Childbirth. 2015; 15: 16, doi: 10.1186/s12884015-0441-3, indexed in Pubmed: 25652550.

6. ACOG Practice Bulletin No. 205: Vaginal Birth After Cesarean Delivery. Obstet Gynecol. 2019; 133 (2): e110-e127. 2019.
7. ACOG practice bulletin number 115: vaginal birth after previous caesarean delivery. Obstet Gynaecol 2010; 116: 450-463.

8. Bottoms SF, Rosen MG, Sokol RJ. The increase in the cesarean birth rate. N Engl J Med. 1980;302(10):559-563, doi: 10.1056/NEJM198003063021006, indexed in Pubmed: 6986017.

9. Silver RM, Landon MB, Rouse DJ, et al. National Institute of Child Health and Human Development Maternal-Fetal Medicine Units Network. Maternal morbidity associated with multiple repeat cesarean deliveries. Obstet Gynecol. 2006; 107(6): 1226-1232, doi: 10.1097/01. AOG.0000219750.79480.84, indexed in Pubmed: 16738145.

10. National Institutes of Health, National Institutes of Health Consensus Development Conference Panel. National Institutes of Health Consensus Development conference statement: vaginal birth after cesarean: new insights March 8-10, 2010. Obstet Gynecol. 2010; 115(6): 1279-1295, doi: 10.1097/AOG.0b013e3181e459e5, indexed in Pubmed: 20502301.

11. Rossi AC, D'Addario V. Maternal morbidity following a trial of labor after cesarean section vs elective repeat cesarean delivery: a systematic review with metaanalysis. Am J Obstet Gynecol. 2008; 199(3): 224-231, doi: 10.1016/j.ajog.2008.04.025, indexed in Pubmed: 18511018.

12. Bangal VB, Giri PA, Shinde KK, et al. Vaginal birth after cesarean section. N Am J Med Sci. 2013; 5(2): 140-144, doi: 10.4103/1947-2714.107537, indexed in Pubmed: 23641377.

13. Phelan JP, Clark SL, Diaz F, et al. Vaginal birth after caesarean. Am J Obstet Gynecol 1987; 157: 1510-1515.

14. Hoskins IA, Gomez JL. Correlation between maximum cervical dilatation at cesarean delivery and subsequent vaginal birth after cesarean delivery. Obstet Gynecol. 1997; 89(4): 591-593, doi: 10.1016/s0029-7844(97)00046-x, indexed in Pubmed: 9083318.

15. McMahon MJ, Luther ER, Bowes WA, et al. Comparison of a trial of labor with an elective second cesarean section. N Engl J Med. 1996; 335(10):689-695, doi: 10.1056/NEJM199609053351001, indexed in Pubmed: 8703167.

16. Shipp T. Interdelivery interval and risk of symptomatic uterine rupture. Obstetrics \& Gynecology. 2001; 97(2): 175-177, doi: 10.1016/s00297844(00)01129-7.

17. Soni A, Sharma C, Verma S, et al. A prospective observational study of trial of labor after cesarean in rural India. Int J Gynaecol Obstet. 2015; 129(2): 156-160, doi: 10.1016/j.ijgo.2014.11.007, indexed in Pubmed: 25801195.

18. Bellows $\mathrm{P}$, Shah U, Hawley L, et al. Evaluation of outcomes associated with trial of labor after cesarean delivery after a change in clinical practice guidelines in an academic hospital. J Matern Fetal Neonatal Med. 2017; 30(17): 2092-2096, doi: 10.1080/14767058.2016.1237498, indexed in Pubmed: 27650923.

19. Studsgaard A, Skorstengaard M, Glavind J, et al. Trial of labor compared to repeat cesarean section in women with no other risk factors than a prior cesarean delivery. Acta Obstet Gynecol Scand. 2013; 92(11): 1256-1263, doi: 10.1111/aogs.12240, indexed in Pubmed: 23962339.

20. Guise JM, Denman MA, Emeis C, et al. Vaginal birth after cesarean: new insights on maternal and neonatal outcomes. Obstet Gynecol. 2010; 115(6): 1267-1278, doi: 10.1097/AOG.0b013e3181df925f, indexed in Pubmed: 20502300.

21. Landon MB, Spong CY, Thom E, et al. National Institute of Child Health and Human Development Maternal-Fetal Medicine Units Network. Risk of uterine rupture with a trial of labor in women with multiple and single prior cesarean delivery. Obstet Gynecol. 2006; 108(1): 12-20, doi: 10.1097/01.AOG.0000224694.32531.f3, indexed in Pubmed: 16816050.

22. Senturk MB, Cakmak Y, Atac $\mathrm{H}$, et al. Factors associated with successful vaginal birth after cesarean section and outcomes in rural area of Anatolia. Int JWomens Health. 2015; 7: 693-697, doi: 10.2147/IJWH.S83800, indexed in Pubmed: 26203286.

23. Landon MB, Leindecker S, Spong CY, et al. National Institute of Child Health and Human Development Maternal-Fetal Medicine Units Network. The MFMU Cesarean Registry: factors affecting the success of trial of labor after previous cesarean delivery. Am J Obstet Gynecol. 2005; 193(3 Pt 2): 1016-1023, doi: 10.1016/j.ajog.2005.05.066, indexed in Pubmed: 16157104.

24. Jongen VH, Halfwerk MG, Brouwer WK. Vaginal delivery after previous caesarean section for failure of second stage of labour. Br J Obstet Gynaecol. 1998; 105(10): 1079-1081, doi: 10.1111/j.1471-0528.1998. tb09939.x, indexed in Pubmed: 9800930. 